УДК 130.1

DOI 10.18413/2712-746X-2020-44-3-420-426

\title{
Истина и история в «феноменологии духа» Гегеля
}

\author{
Павлов П.В. \\ Южно-Российский государственный политехнический университет \\ им. М.И. Платова, \\ Россия, 346428, г. Новочеркасск, ул. Просвещения, 132 \\ E-mail: pvpavlov2006@yandex.ru
}

\begin{abstract}
Аннотация. Прослежен драматический путь истории духа (от «прекрасной нравственной жизни» античности до отчужденного мира буржуазного общества, утвержденного Французской революцией) и его возвращение к «себе», своей истине - «абсолютному знанию», в котором осуществляется понимание исторических форм, раскрывается их подлинный смысл. При этом подчеркивается методологическая значимость опосредования истины и истории, благодаря которому истина и абсолютное не редуцируются к историческим формам и вместе с тем сохраняют их богатство и многообразие, драматизм их становления. В контексте гегелевского понимания истины как «раскрытой реальности» особое внимание уделено обсуждению проблемы соотношения методов «Феноменологии духа» и феноменологии как направления современной мысли.
\end{abstract}

Ключевые слова: Гегель, истина, история, дух, сознание, абсолютное знание, понятие.

Для цитирования: Павлов П.В. 2020. Истина и история в «феноменологии духа» Гегеля. NOMOTHETIKA: Философия. Социология. Право. 45 (3): 420-426. DOI 10.18413/2712-746X-202044-3-420-426

\section{Truth and history in Hegel’s «phenomenology of spirit»}

\author{
Pavel V. Pavlov \\ Platov South-Russian State Polytechnic University, \\ 132 Prosvescheniya St, Novocherkassk, 346428, Russia \\ E-mail: pvpavlov2006@yandex.ru
}

\begin{abstract}
The article is devoted to the problem of truth and history in Hegel's «Phenomenology of Spirit». The dramatic path of the history of the spirit is traced (from the «beautiful moral life» of antiquity to the alienated world of bourgeois society, approved by the French Revolution) and its return to «itself», its truth. The sphere of truth is «absolute knowledge», in which the understanding of historical forms is carried out, their true meaning is revealed. At the same time, the author of the article emphasizes the methodological significance of mediating truth and history. Thanks to this mediation, truth and absolute do not reduce to historical forms and at the same time preserve their richness and diversity, the dramatic nature of their formation. In the context of Hegel's understanding of truth as an «open reality», the article focuses on the problem of the attitude between the methods of «Phenomenology of Spirit» and phenomenology as a direction of modern thought.
\end{abstract}

Keywords: Hegel, truth, history, spirit, consciousness, absolute knowledge, notion.

For citation: Pavlov P.V. 2020. Truth and history in Hegel's «phenomenology of spirit». NOMOTHETIKA: Philosophy. Sociology. Law series. 45 (3): 420-426 (in Russian). DOI 10.18413/2712-746X-2020-44-3-420-426 
Гегелевское классическое определение истинного как целого из «Феноменологии духа» вряд ли покажется созвучным «современности», нынешнему «духу времени». Современному «духу», скорее всего, ближе хайдеггеровское понимание истины как «моего» «существования», без которого «не было никакой истины и не будет никакой» [Хайдеггер, 2003, с. 258]. Но у Хайдеггера «раскрывающаяся» истина «моего» «существования», в конечном счете, предстает как ничто, тогда как у Гегеля в «Феноменологии» истина как Абсолют - это результат драматического восхождения духа к себе самому, которое и есть подлинное возвращение к себе и обретение себя. Об этом Гегель вполне определенно пишет в Предисловии к «Феноменологии»: «Об абсолютном нужно сказать, что оно по существу есть результат, что оно лишь в конце есть то, что есть оно поистине; и в том-то и состоит его природа, что оно есть действительное, субъект или становление самим собою для себя» [Гегель, 2000, с. 16].

Как полагает Георг Лукач, гегелевская «Феноменология» - это «Одиссея духа», «возвращение духа домой». В свое время Шеллинг в «Системе трансцендентального идеализма» охарактеризовал свою философию именно как «одиссею духа» [Шеллинг, 1987]. Однако, уверен Лукач, это шеллинговское «остроумное» определение в большей степени подходит к «Феноменологии», которая по масштабу и глубине проблематики сопоставима лишь с «Фаустом» Гете.

Для Лукача «Фауст» и «Феноменология духа» - эти «величайшие художественные и интеллектуальные достижения классического периода в Германии» - тесным образом связаны между собой [Lukács, 1979, р. 176]. Подобно «Фаусту», «Феноменология»сложное, наполненное трагическими противоречиями «путешествие» человека и освоение им «родового опыта человечества», поиск абсолютного знания и восхождение к истине. При этом, полагает Лукач, и у Гете, и у Гегеля «драма человеческого рода» разыгрывается через «цепочку индивидуальных трагедий»: трагедии в «микрокосме» человека раскрывают подлинное историческое движение «макрокосма» человечества. Драматический путь восхождения к целому - путь, через который и раскрывается гегелевское понимание истины и истории.

И действительно, в «Феноменологии» представлена впечатляющая картина исторических странствий духа, его трагических коллизий. Гегель с явной симпатией описывает античное «нравственное царство», «прекрасную нравственную жизнь», в которой существовала непосредственная гармония человека и мира, их равновесие. Не случайно, как заметил Лукач, «изображение прекрасной и непосредственной нравственности греческого мира» является «вершиной в литературном творчестве Гегеля» [Лукач, 1987, с. 533].

Однако дух не может вечно пребывать в этой непосредственности, он должен «снять прекрасную нравственную жизнь и, пройдя ряд формообразований, достигнуть знания себя самого» [Гегель, 2000, с. 224]. Античная классическая форма с ее «непорочным и незапятнанным миром» с неизбежностью уходит в прошлое, уступая место миру отчужденному. Так, уже в период Римской империи мир всеобщего распадается на множество «атомов», «лиц»: непосредственная нравственная жизнь сменяется абстрактным правом, а человек становится «правовым лицом». Своей же явной полноты отчуждение, «отчужденный от себя дух» достигает в буржуазном обществе.

У Гегеля весьма интересно представлен переход от феодального сословного общества - через этап абсолютной монархии - к новому миру буржуазного общества, порожденному Французской революцией. Так, для феодала - «гордого вассала» с его «благородным сознанием» - добродетелью является героизм служения в интересах государственной власти. Однако «благородное сознание» феодала сменяется лестью придворного при абсолютной монархии. «Героизм безмолвного служения, - пишет Гегель, - превращается в героизм лести» [Гегель, 2000, с. 261]. При этом государственная власть постепенно переходит в «буржуазное» богатство, которое становится всеобщей силой. Власть богатства разлагает представления прежнего мира: «благородное сознание» переходит в «низменное», «хорошее» и «дур- 
ное» становятся относительными. По словам Мих. Лифшица, «всеобщее брожение», «отделяющее» феодальный мир «от капиталистической эпохи, разложение старых сословий, превращение богатства в самостоятельную и господствующую силу, - все это растворяет противоположность «благородного» и «низкого», превращает одно в другое, колеблет все устойчивые различия. Гегель с удивительным реализмом... изображает процесс развития цивилизации, или, как он сам выражается, «образования» (Bildung)» [Лифшиц, 1984, с. 152].

Ярким выражением этого «реального мира образованности», его «духа», который характеризуется Гегелем как «абсолютное и всеобщее извращение и отчуждение действительности и мысли» [Гегель, 2000, с. 266], становится «разорванное сознание». В своем «красноречии» «разорванное сознание» осуществляет «извращение всех понятий и реальностей, всеобщий обман самого себя и других» [Гегель, 2000, с. 267]. При этом «бесстыдство, с каким высказывается этот обман», оказывается «величайшей истиной» (таковы речи циничного племянника Рамо - персонажа известной повести Дидро, которую цитирует Гегель).

Французская революция осуществляет радикальный «переворот действительности»: упраздняя старый мир, она выступает как «абсолютная свобода». Эта «абсолютная свобода», в которой отменены сословия, предстает теперь всеобщей господствующей формой. Как подчеркивает Гегель, «нераздельная субстанция абсолютной свободы возводится на мировой престол, и никакая сила не в состоянии оказать ей сопротивления» [Гегель, 2000, с. 300].

Однако эта «абсолютная свобода» оборачивается «ужасом». И не только ужасом революционного террора, когда смерть становится «самой пошлой» и «холодной», лишенной, по словам Гегеля, «внутреннего объема и наполнения», но, прежде всего, ужасом отчуждения и пустоты в буржуазном мире. Этот отчужденный мир оказывается расколотым на крайности - изолированных, разобщенных индивидов («ненаполненные точки», «своенравная точечность самосознания») и противостоящую им абстрактную и «непреклонную холодную всеобщность». Тем самым всеобщая «абсолютная свобода» становится высшей фазой отчуждения, оборачиваясь чистой негативностью - «негативным действованием», «фурией исчезновения».

В «Феноменологии духа» Гегель уже распрощался с иллюзиями своей молодости о возрождении античности (отношение к античности у молодого Гегеля обстоятельно рассмотрено в фундаментальном труде Г. Лукача [1987], а также в статьях Мих. Лифшица [2012]). Французская революция не привела к возрождению «прекрасной нравственности», но закрепила буржуазную действительность. Гегель «примиряется» с этой действительностью, стремясь осмыслить ее реальные противоречия. Впрочем, в «Феноменологии» Гегель полагает, что доведенные до крайности Французской революцией полюса отчуждения «примиряются» в «моральном духе» современной ему Германии. «Абсолютная свобода», как выражается философ, из своей «разрушающей действительности» переходит в «другую страну обладающего самосознанием духа» [Гегель, 2000, с. 305].

Комментируя этот раздел «Феноменологии», посвященный «моральности», Г. Лукач определяет его содержание как «утопию Гегеля о Германии под господством Наполеона» [Лукач, 1987, с. 549]. Германия, освобожденная Наполеоном от феодализма, надеется Гегель, может явить «правильную», более «гармоничную» форму буржуазного общества, сглаживающую и примиряющую противоречия буржуазной действительности, порожденной Французской революцией. Правда, как полагает Лукач, раздел «Феноменологии» о «моральном духе» является весьма абстрактным, бедным по содержанию. «Моральный дух» оказывается утопией, лишенной положительного и конкретного общественного содержания. И эта «пустота», полагает Лукач, по сути является отражением современной Гегелю социально-политической действительности (характерно, что уже после поражения Наполеона гегелевские надежды, выраженные в «Феноменологии духа», потерпят крушение и «приведут к тому, что Гегелю придется довольствоваться после глубокого разочарования окончательно утвердившейся прозой капитализма» [Лукач, 1987, с. 448]). 
Но остается ли что-то подлинно реальное, помимо этой пустоты и абстрактности? Ответ Гегеля: реальность абсолютного, в котором запечатлеваются подлинные достижения мировой истории, проясняется и раскрывается их истина, осуществляется их действительное понимание. В этом понимании и состоит важнейший смысл гегелевского учения об абсолютном знании - «знании, постигающем в понятии». Здесь, как пишет Лукач, «при свете абсолютного знания» проясняются те связи, «которые направляли и определяли историческую борьбу героев всемирно-исторической драмы» [Лукач, 1987, с. 555]. В историческом движении духа «образы мира» - «актеры всемирно-исторической драмы», которые, «сражаясь, побеждая или подчиняясь», непосредственно переживают исторический процесс, «свою историческую современность», тогда как в сфере абсолютного знания «развертывается грандиозный эпос о взаимосвязях всемирной истории как завершенном процессе» [Лукач, 1987, с. 554]. Абсолютное знание как завершение осуществляет действительное понимание истории. И хотя это понимание не возрождает непосредственное бытие ушедших исторический форм, однако оно впервые во всей полноте открывает и проясняет их истинный смысл.

Так, невозможно в современном отчужденном мире непосредственно «воскресить» античную классику, о чем весьма проникновенно пишет Гегель, говоря о «судьбе» античных произведений искусства: «судьба не дает нам их мира, не дает весны и лета нравственной жизни, в которой они цвели и зрели, а дает лишь туманное воспоминание об этой действительности» [Гегель, 2000, с. 380]. Однако, продолжает он, «дух судьбы, который предоставляет нам эти произведения искусства» в своем воспоминании, «самоуглублении» оказывается «нечто большим», нежели «нравственная жизнь и действительность того народа», которая исторически породила эти произведения искусства. В своем воспоминании «самоуглубленный» дух сохраняет эти формы в качестве «более высокой формы субстанции», собирает их «в один пантеон, в дух, сознающий себя самого как дух» [Гегель, 2000, с. 380].

«Уход внутрь себя» духа - это его завершение, в котором он в совершенстве знает себя, «то, что он есть». В знании дух «замыкает» движение своих исторических форм, достигая «чистой стихии своего наличного бытия - понятия» [Гегель, 2000, с. 408]. Так перед нами, согласно Гегелю, раскрывается истина, абсолютное знание - «история, постигнутая в понятии».

В своих лекциях о «Феноменологии духа» Александр Кожев неоднократно подчеркивает, что истина для Гегеля - это раскрытая реальность. «Мудрец», «гегелевский ученый», как пишет Кожев, «полностью и окончательно примирился со всем, что есть, он безоглядно отдается Бытию и полностью открывается Реальному, не оказывая ему никакого сопротивления. Его задача - быть идеально гладким и бесконечно протяженным зеркалом: он не занимается рефлексией, «отражая» Реальное, это само Реальное мыслит в нем, отражаясь в его сознании и раскрываясь в своей собственной диалектической структуре с помощью речи Мудреца, описывающей его без каких-либо искажений» [Кожев, 2003, с. 561]. Иными словами, речь идет о том, что гегелевский метод предполагает устранение всякого субъективного вмешательства в предмет и дает самой действительности, самому предмету раскрыться и «заговорить» в своей истине.

Впрочем, следует отметить, что А. Кожев пытается предельно сблизить метод «Феноменологии духа» с феноменологией Эдмунда Гуссерля. Более того, Кожев весьма категорично утверждает, что гегелевский метод является «феноменологическим в гуссерлевском значении термина» [Кожев, 2003, с. 556]. Метод Гегеля он именует «чисто созерцательным и описательным», то есть по сути «феноменологическим» в современном понимании - в смысле Гуссерля и его последователей. Только лишь «по неведению», полагает 
Кожев, собственный феноменологический метод Гуссерль «ошибочно противопоставил гегелевскому» [Кожев, 2003, с. 581].

Конечно, Гуссерль прямо не обращается к гегелевской философии. Однако уже Мартин Хайдеггер постоянно обращается к Гегелю, проводит «разбирательство» с ним, в том числе, комментируя его «Феноменологию духа» [Хайдеггер, 2015]. Наконец, герменевтическая концепция Х.-Г. Гадамера стремится «интегрировать» гегелевский метод: диалектика, полагает Гадамер, «должна вернуться к герменевтике» [Gadamer, 1976, p. 99]. При этом философская герменевтика понимает себя не только в качестве «преемницы» феноменологии Гуссерля, но также и гегелевской мысли. По крайней мере, для Гадамера актуализируется задача перебросить «отсутствующий мост между феноменологией духа Гегеля и феноменологией трансиендентальной субъективности Гуссерля» [Gadamer, 1990, p. 258].

Однако Гадамер не случайно говорит именно об «отсутствующем мосте» между феноменологиями Гегеля и Гуссерля. Ведь вопреки категоричному утверждению А. Кожева, можно сказать, что гегелевская феноменология, его «наука об опыте сознания» существенно отлична от феноменологической концепции и методологии Гуссерля. И суть дела заключается, прежде всего, в принципиально различных подходах к пониманию истины и сознания. Так, для Гуссерля сознание предстает как «одинокая ментальная жизнь», сфера собственных интенциональных переживаний. Именно в этих переживаниях непосредственно открывается («усматривается») истина, которая выступает как интуитивная очевидность.

Совершенно иначе обстоит дело в «науке об опыте сознания» Гегеля: непосредственная достоверность, несмотря на кажущуюся очевидность, вовсе не есть истина, но лишь самый простейший, начальный этап движения сознания. В этом движении достоверность «сама выдает себя за истину самую абстрактную и самую бедную» [Гегель, 2000, c. 54]. Сознание преодолевает непосредственную достоверность и отправляется в сложный путь восхождения к самому себе, к своей истине как иелому. На этом пути оно вбирает в себя все богатство мира, многообразие его исторических формообразований, которые, как подчеркивает Гегель, есть формы действительного мира, а не формы «одного лишь сознания» [Гегель, 2000, с. 224]. И, наконец, осуществляя себя через эти действительные формы, сознание обретает свою истину, становится абсолютным знанием.

Э. Гуссерль в качестве метода поиска истинного знания и абсолютного бытия предлагает трансцендентально-феноменологическую редукцию. Мир «теряется», заключается в «скобки», в результате чего обретается «чистая жизнь сознания», одинокая «трансцендентальная субъективность», которая и выступает в качестве абсолютного источника всех смыслов. Исходя из «трансцендентального солипсизма», Гуссерль стремится, как это представлено в «Картезианских размышлениях» [Husserl, 1973], конституировать интерсубъективный мир культуры. При этом «мое собственное» трансцендентальное «Я» оказывается тем абсолютным центром, который конституирует интерсубъективный мир, обеспечивая его достоверность.

Иной путь предлагает Гегель: для него истина и абсолютное знание - это результат восхождения по лестнице мирового опыта. В этом восхождении, которое наполнено «серьезностью, страданием, терпением», сознание превозмогает собственную ограниченность и односторонние моменты, «вмещает» в себя драму мировой истории со всеми ее противоречиями и трагическими коллизиями. Сознание в гегелевской «Феноменологии» тем самым выходит за пределы своей субъективности и через многообразные исторические формообразования («гештальты») достигает «понятия», становится истинным, понимающим сознанием. Как подчеркивает Гегель, «благодаря движению понятия» этот путь восхождения полностью охватывает «мировместимость (vollständige Weltlichkeit) сознания в ее необходимости» [Гегель, 2000, с. 24]. 
И здесь следует отметить принципиальный момент в гегелевском понимании соотношения истины и истории. Речь идет об опосредовании, имеющем важное методологическое значение. Истина отнюдь не редуцируется к исторически меняющимся формам духа, не растворяется в их становлении. Абсолютное, раскрывая истинное содержание формообразований истории и осуществляя их понимание, вместе с тем сохраняет свою существенную несводимость, опосредование. Ведь, как пишет Г. Лукач, «актуальная историческая действительность... не тождественна ее истинному содержанию» [Лукач, 1987, с. 558]. Здесь перед нами «различение и одновременно объединение» исторических форм и абсолюта, их диалектическое единство, которое «вместе с тем включает в себя диалектическое различение и противопоставление» [Лукач, 1987, с. 558].

Именно благодаря этому диалектическому опосредованию «всеохватывающий историзм» «Феноменологии», по словам Лукача, и не завершается «голым релятивизмом». Исторический релятивизм возможен в том случае, когда история утрачивает «моменты» истины, оказывается лишенной своего абсолютного «измерения». В этом случае история оборачивается «чистой негативностью» и бессмысленным становлением. У Гегеля же в его «Феноменологии» «моменты» истины и абсолюта осуществляются в самой истории, хотя полностью и не совпадают с ней. «Моменты» истины сохраняют свое отличие, образуя высшую сферу «абсолютного знания».

Таким образом, в гегелевской «Феноменологии» истина и история, Абсолют и исторически меняющиеся формообразования духа составляют опосредованное единство единство, которое с необходимостью предполагает также и их диалектическое различие. Сменяющие друг друга исторические формы духа отнюдь не тождественны истинному и абсолютному содержанию, которое раскрывается в истории. И вместе с тем в Абсолюте «абсолютном знании» и понятии - сохранено это многообразие форм и драматический путь их становления. И без этого опосредованного становления, без этого богатства и драматизма исторических форм абсолютный дух «был бы безжизненным и одиноким», как весьма поэтично пишет Гегель в заключительных строках своей «Феноменологии».

\section{Список литературы}

1. Гегель Г.В.Ф. 2000. Феноменология духа. М., Наука, 495 с.

2. Кожев А. 2003. Введение в чтение Гегеля. СПб., Наука, 792 с.

3. Лифшиц Мих. 2012. О Гегеле. М., «Грюндриссе», 304 с.

4. Лифшиц Мих. 1984. Собрание сочинений. В 3 т. Том 1. М., Изобразительное искусство, $432 \mathrm{c}$.

5. Лукач Д. 1987. Молодой Гегель и проблемы капиталистического общества. М., Наука, $616 \mathrm{c}$.

6. Хайдеггер М. 2003. Бытие и время. Харьков, «Фолио», 512 с.

7. Хайдеггер М. 2015. Гегель. СПб.: «Владимир Даль», 320 с.

8. Шеллинг Ф.В.Й. 1987. Система трансцендентального идеализма. В кн.: Шеллинг Ф.В.Й. Сочинения в 2 т. Т. 1. М., Мысль: 227-489.

9. Gadamer H.-G. 1976. Hegel's Dialectic: Five Hermeneutical Studies. Translated by P. Christopher Smith. New Haven, Yale University Press, 118 p.

10. Gadamer H.-G. 1990. Wahrheit und Methode: Grundzüge einer philosophischen Hermeneutik. Gesammelte Werke. Band 1. Tübingen, J.C.B. Mohr (Paul Siebeck), 495 p.

11. Husserl E. 1973. Cartesianische Meditationen. Husserliana. Band 1. Haag, Martinus Nijhoff, $249 \mathrm{p}$. $258 \mathrm{p}$.

12. Lukács G. 1979. Goethe and his Age. Translated by Robert Anchor. London, Merlin Press,

\section{References}

1. Gegel' G.V.F. 2000. Fenomenologiya dukha [Phenomenology of Spirit]. Moscow, Nauka, 495 p.

2. Kozhev A. 2003. Vvedenie v chtenie Gegelya [Introduction to the Reading of Hegel]. SaintPetersburg, Publ. Nauka, 792 p. 
3. Lifshits Mikh. 2012. O Gegele [About Hegel]. Moscow, Publ. Gryundrisse, 304 p.

4. Lifshits Mikh. 1984. Sobranie sochineniy. [Collected works]. In 3 vol. Vol. 1. Moscow, Publ. Izobrazitel'noe iskusstvo, $432 \mathrm{p}$.

5. Lukach D. 1987. Molodoy Gegel' i problemy kapitalisticheskogo obshchestva [Young Hegel and the problems of capitalist society]. Moscow, Publ. Nauka, 616 p.

6. Khaydegger M. 2003. Bytie i vremya [Being and Time]. Khar'kov, Publ. Folio, 512 p.

7. Khaydegger M. 2015. Gegel' [Hegel]. Saint-Petersburg, Publ. Vladimir Dal', 320 p.

8. Shelling F.V.Y. 1987. Sistema transtsendental'nogo idealizma [System of Transcendental Idealism]. In: Shelling F.V.Y. [Schelling F.W.J.] Works in 2 vol. Vol. 1. Moscow, Publ. Mysl': 227-489.

9. Gadamer H.-G. 1976. Hegel's Dialectic: Five Hermeneutical Studies. Translated by P. Christopher Smith. New Haven, Yale University Press, 118 p.

10. Gadamer H.-G. 1990. Wahrheit und Methode: Grundzüge einer philosophischen Hermeneutik. Gesammelte Werke. Band 1. Tübingen, J.C.B. Mohr (Paul Siebeck), 495 p. Nijhoff, 249 p.

11. Husserl E. 1973. Cartesianische Meditationen. Husserliana. Band 1. Haag, Martinus

12. Lukács G. 1979. Goethe and his Age. Translated by Robert Anchor. London, Merlin Press, $258 \mathrm{p}$.

\section{ИНФОРМАЦИЯ ОБ АВТОРЕ}

Павлов Павел Викторович, доктор философских наук, доцент, Профессор кафедры управления персоналом Южно-Российского государственного политехнического университета (НПИ) им. М.И. Платова. г. Новочеркасск, Россия

\section{INFORMATION ABOUT THE AUTHOR}

Pavel V. Pavlov, Full Doctor of Philosophy, Associate Professor, Platov South-Russian State Polytechnic University, Professor of Personnel Management Department, Novocherkassk, Russia 